\title{
A INSERÇÃO DA EDUCAÇÃO AMBIENTAL NO CURRÍCULO ESCOLAR
}

\author{
The insertion of Environmental Education in the school curriculum \\ Aline Gomes dos Santos, Crisliane Aparecida Pereira Santos \\ Universidade do Estado da Bahia - UNEB/Campus IX
}

\begin{abstract}
Resumo
A escola pode constituir um espaço para o desenvolvimento da Educação Ambiental (EA), objetivando formar cidadãos conscientes, capazes de enfrentar os desafios da realidade socioambiental. O principal objetivo deste artigo é analisar a EA sob a perspectiva do currículo escolar, buscando mostrar como a EA tem sido inserida no currículo das escolas brasileiras. A metodologia de pesquisa se baseou na coleta de dados secundários por meio da seleção de 38 documentos (artigos científicos, publicações acadêmicas e livros didáticos). A adoção de questionários se revelou como a principal metodologia de trabalho. Com relação às ações executadas, percebeu-se que a EA acontece mediante projetos, disciplinas afins, iniciativa individual do professor ou interdisciplinarmente. A pesquisa permitiu mostrar quais as ações de EA são desenvolvidas nas escolas brasileiras, evidenciando a forma como acontece a inserção desta temática no currículo. Além de considerar que os projetos seguidos da inserção, por meio de disciplinas afins, são ainda os principais mecanismos de desenvolvimento da EA no âmbito escolar.
\end{abstract}

Palavras-chave: currículo, educação ambiental, escola.

Abstract

The school can be a space for the development of Environmental Education (EA), aiming create conscientious citizens, capable to confront the challenges of environmental reality. The main aim of this article to analyze the EA from the perspective of the school curriculum, seeking to show out how EA has been included in the curriculum of brazilian schools. The research methodology was based on secondary data collection by selecting 38 documents (scientific articles, academic journals and textbooks). The adoption of questionnaires is revealed as the main method of work. Regarding respect to actions, it was observed that the EA takes place through projects, related disciplines, individual initiative of the teacher or interdisciplinary. The research allowed to show what EA actions are developed in brazilian schools, showing how happens the inclusion of this theme in the curriculum. In addition to considering the projects followed of inclusion, through related disciplines, are still the main EA development mechanisms in schools.

Keywords: curriculum, environmental education, school. 


\section{Introdução}

A Educação Ambiental (EA) é um processo de aprendizagem longo e contínuo que busca formar e desenvolver atitudes racionais e responsáveis na perspectiva de criar um novo modelo de relacionamento entre homem e meio ambiente (OLIVEIRA, 2005). Este mesmo pensamento persiste na visão de Carvalho (2006) o qual define a EA como sendo uma preocupação inicial dos movimentos ecológicos com a finitude e a má distribuição dos recursos naturais, preocupação esta que não se aplica apenas ao mau uso destes recursos, mas reflete na formação de cidadãos envolvidos em ações sociais ambientalmente apropriadas.

Um dos maiores campos de atuação da EA é a escola, um espaço privilegiado, onde se pode criar condições e alternativas que estimulem os alunos a terem concepções e posturas cidadãs, cientes de suas responsabilidades e principalmente, integrantes do meio ambiente. Nessa perspectiva, a escola pode constituir um espaço para o desenvolvimento da EA objetivando formar cidadãos conscientes, capazes de enfrentar os desafios da realidade socioambiental (LIMA, 2004).

A EA é uma ação educativa permanente, portanto deve fazer parte da formação cidadã do aluno e do professor. A autoridade da formação de um educador sobre a sua prática é imensa, o que pode até impossibilitar a prática da EA na escola e isso corrobora, ainda mais, a importância de se discutir a formação e a prática do professor em EA (FERREIRA, 2010).

Por outro lado, considera-se um tema relativamente recente, em termos de sua inclusão nos programas de formação docente e também em relação a sua inserção no currículo das escolas. Diante disso, muitas são as dificuldades que o professor encontra para colocar em prática uma educação tão abrangente como é a EA (BONOTTO, 2005). Assim, é importante analisar qual é a relação que existe entre a prática da EA nas escolas e a formação inicial dos professores.

\section{Os PCN's e a prática docente da Educação Ambiental}

No Brasil, os Parâmetros Curriculares Nacionais ( $\mathrm{PCN}^{\prime} \mathrm{s}$ ) norteiam as práticas educativas que visam a implementação da EA no ensino. Nesse contexto, a EA é inserida dentro do tema meio ambiente de forma transversal, argumentando que a problemática dos Temas Transversais atravessa diferentes campos do conhecimento (BRASIL, 1998).

Os PCN's explicitam que a questão ambiental deve ser trabalhada de forma contínua, sistemática, abrangente e integrada e não como áreas ou disciplinas. Isso se explica pelo fato de que o estudo do tema Meio Ambiente remete à necessidade de se recorrer a conhecimentos relativos a diversas áreas do saber (BRASIL, 1998).

Ainda segundo os $\mathrm{PCN}^{\prime}$, na prática pedagógica, interdisciplinaridade e transversalidade se alimentam mutuamente, sendo impossível haver transversalidade sob outra ótica, se não a da interdisciplinaridade. Ambas se fundamentam na crítica de um conhecimento fragmentado e isento da realidade. Dessa forma, a interdisciplinaridade questiona a segmentação do conhecimento, referindose a uma relação entre as disciplinas, enquanto a prática transversal diz respeito à possibilidade de a prática educativa estabelecer uma relação entre aprender na realidade e da realidade (BRASIL, 1998).

Com a proposta de se dar ao currículo uma dimensão social e contemporânea, ao discutir temas relevantes em determinado contexto histórico-social, foi instaurada perspectiva dos temas transversais. A transversalidade da questão ambiental é justificada pelo fato de que seus conteúdos, de caráter tanto conceitual (conceitos, fatos e princípios), como procedimental (relacionados com os processos de produção e de ressignificação dos conhecimentos) e, também atitudinal (valores, normas e atitudes) possuem determinadas características em comum: não configuradas como áreas ou 
disciplinas, as quais são abordadas a partir de uma multiplicidade de áreas e, ligadas ao conhecimento adquirido por meio da experiência, com repercussão direta na vida cotidiana (OLIVEIRA, 2007).

Esta temática está de acordo com os PCN's, haja vista que, segundo este documento oficial, a questão ambiental deve ser trabalhada de forma contínua e integrada com as diversas áreas do conhecimento e não como disciplinas rígidas. Isso se explica pelo fato de que o estudo do tema Meio Ambiente remete à necessidade de se recorrer a conhecimentos relativos a diversas áreas do saber (BRASIL, 1998). E, diante dos múltiplos argumentos, o tratamento dado às questões ambientais pelos PCN's não é um consenso geral.

A prática da EA no ensino formal tem enfrentado inúmeros desafios. Para melhor explicá-los, Carvalho (2005, p. 59) postula o seguinte questionamento: "Afinal, como ocupar um lugar na estrutura escolar desde essa espécie de não lugar que é a transversalidade?" Para este autor, ao se constituir a EA como tema transversal, ela pode tanto ganhar o significado de estar em todo lugar, como também não pertencer a nenhum dos lugares dentro da estrutura curricular.

Mediante a dificuldade de praticar a transversalidade, Cuba (2010) defende que EA deve ser tratada de modo científico, oferecida em forma de disciplina específica, porém sem perder sua essência interdisciplinar. Isso também é defendido por Santos (2007) ao afirmar que uma das formas de aplicação do estudo dos problemas relacionados ao meio ambiente se dá por meio de uma disciplina específica a ser introduzida nos currículos das escolas, podendo assim alcançar a mudança de comportamento de um grande número de alunos, tornando-os influentes na defesa do meio ambiente, além de ecologicamente equilibrados e saudáveis.

As disciplinas ditas especiais cumprem o papel de criar um maior tempo de trabalho e proporcionar um espaço fixo de diálogo para as problemáticas ambientais (TRAJBER e MENDONÇA, 2007). Conceitualmente, a disciplinarização da EA pode representar uma visão limitadora desta ciência, porém sua inexistência pode implicar o esvaziamento da importância e efetiva presença da EA na educação escolar (ROSSI e LEAL, 2012).

Macedo (1998) defende que, para que os temas transversais funcionem como eixo integrador das diferentes áreas do currículo, e deste com a realidade social, seria necessário uma articulação entre as áreas e os temas transversais, fundamentados na seleção e organização do conhecimento em cada área. O mesmo autor ainda revela que os temas transversais deveriam ser o eixo estrutural do currículo. Entretanto, na realidade, são postos em um patamar de importância inferior ao das disciplinas na organização do guia curricular.

O que parece transparecer dessas observações é que os PCN's não embutem, em sua lógica, a centralidade que se afirma terem os temas transversais. E assim, um dos argumentos usados para fundamentar os temas transversais é que o currículo escolar baseado em disciplinas fixas causa um isolamento do conhecimento e reduz a EA a uma mera transmissão de informações sobre o meio ambiente. Porém, Leff (2001, p. 261) afirma que:

\footnotetext{
“O ensino tradicional básico falha não tanto por ser disciplinar, mas por não impulsionar e orientar as capacidades cognitivas, criativas dos alunos, e por estar desvinculado dos problemas do contexto sociocultural e ambiental. A pedagogia ambiental deve gerar um pensamento da complexidade que seja crítico, participativo e propositivo".
}

Como se pode observar, a maioria dos autores concorda com a ideia de que a EA deve ser trabalhada na perspectiva transversal e interdisciplinar. Oliveira (2007) possui posicionamento similar ao afirmar que ninguém mais se atreve a propor a EA como mais uma disciplina do currículo escolar e muito menos a imaginá-la sendo desenvolvida por um único professor. Porém, esse consenso existe apenas em especialistas ligados à área ambiental, como ambientalistas e professores acadêmicos e, entre os professores da educação básica, a dúvida ainda persiste.

O desejo de que haja um espaço específico, para que essas questões inegavelmente importantes sejam tratadas, reflete a busca por um espaço curricular próprio que forme um eixo capaz de reunir e articular o currículo e os elementos orientadores da ação do professor. Parece que o desejo aí contido não é a criação de uma disciplina em si mesma, mas sim, o de encontrar uma alternativa que viabilize 
a inserção do ambiental no currículo, pois esse é o modelo que conhecemos e ao qual estamos familiarizados. E isso reflete a ânsia que existe em muitos educadores em ver um espaço fixo e bem delimitado para a EA no ensino formal (OLIVEIRA, 2007).

Entender de que maneira a EA tem sido inserida no currículo escolar é de suma importância porque gera subsídios para novas práticas educativas na área, além de elucidar os problemas nas formas como a EA tem sido trabalhada nas escolas brasileiras. A prática da EA no ensino formal tem enfrentado muitos desafios e existem obstáculos a serem transpostos para que esta se firme como prática educativa capaz de atingir os objetivos propostos pelos PCN's.

A EA esbarra em muitos problemas na tentativa de inserção no currículo escolar. Grande parte das escolas brasileiras não tem um projeto educativo que contemple a problemática ambiental, e assim não pode oferecer aos professores condições propícias para trabalhar coletivamente e de forma integrada. Esse cenário dificulta um trabalho efetivo com base na transversalidade e a interdisciplinaridade, ideais propostos para a prática da EA (BRASIL, 2001). Desse modo, o objetivo deste trabalho é analisar a EA sob a perspectiva do currículo escolar, buscando averiguar como a EA tem sido inserida no currículo das escolas brasileiras.

\section{Metodologia}

A presente pesquisa se caracteriza como do tipo qualitativa, pois leva em consideração a compreensão dos fenômenos sociais, significado e a intencionalidade que os envolvidos atribuem as suas ações no meio em que vivem e que se relacionam, considerando os vínculos indissociáveis das ações particulares com o contexto social em que estes acontecem (SANTOS, 2007).

A metodologia de pesquisa se baseou na coleta de dados secundários por meio da seleção de 38 documentos de diferente natureza: artigos científicos, publicações acadêmicas (monografias, dissertação de mestrado) e livros didáticos (PÁDUA E TABANEZ, 1998; LEFF, 2001; REIGOTA, 2004; CARVALHO, 2006), que pudessem nortear o andamento do trabalho, sendo priorizados os aspectos sobre a definição e histórico da EA, sua inserção no currículo escolar, sua questão legal e orientações curriculares.

Desses 38, 12 foram artigos de revistas, 10 dissertações de mestrado, 6 monografias e 10 artigos apresentados em eventos científicos. Esses documentos têm como finalidade visualizar como a EA tem sido inserida nas escolas, mediante a ação executada e a metodologia aplicada, para somente então permitir a compreensão dos aspectos da formação dos alunos em EA.

\section{Resultados e Discussão}

Dos 38 documentos selecionados, apenas um $(2,6 \%)$ usou como metodologia de pesquisa a visita à escola objeto do estudo. Os outros, $37(97,4 \%)$ utilizaram como metodologia principal a aplicação de questionários ou entrevistas (FIGURA 1).

Para Lôbo (2013) a aplicação de questionários apresenta algumas vantagens, como a capacidade de alcançar um maior número de pessoas, garantindo o seu anonimato, e ainda permite que a sua resolução aconteça em qualquer lugar, com ou sem a presença do pesquisador. Os questionários possibilitam ainda a obtenção de respostas mais precisas e com menos distorções e dá ainda mais liberdade ao ser respondido por ser anônimo.

Uma das maiores inquietações em relação à EA escolar é como ela está inserida no currículo das escolas brasileiras. Os documentos selecionados para a pesquisa possibilitaram um vislumbre de como a EA é desenvolvida nos currículos das escolas brasileiras. Neste sentido, verificou-se que a adoção de questionários ou entrevistas se revelou como a principal metodologia de trabalho. 


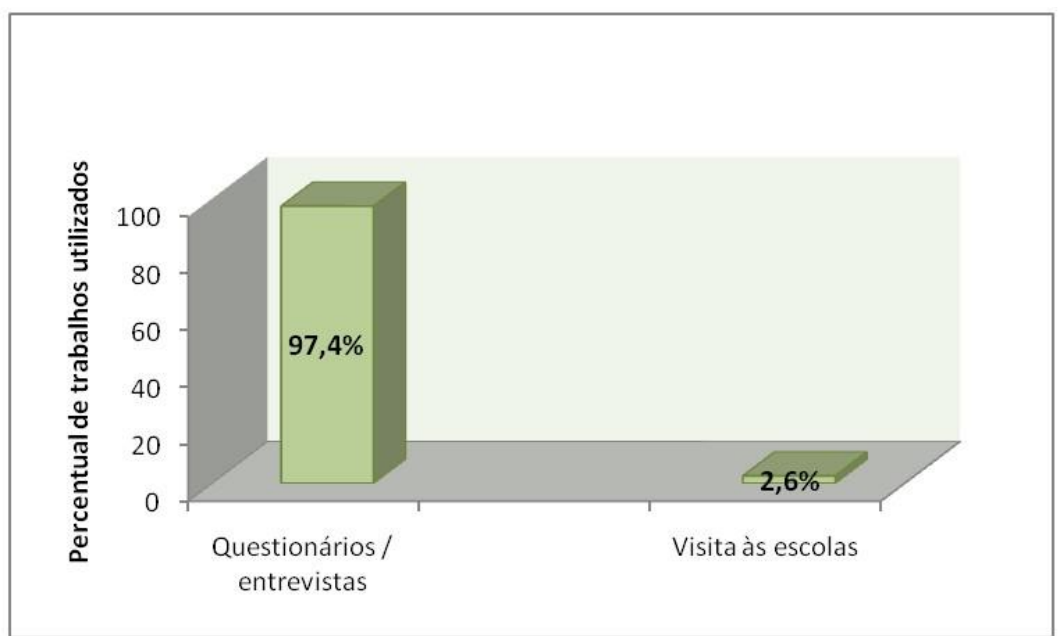

Figura 1 - A Educação Ambiental e as metodologias utilizadas pelos pesquisadores/professores nas escolas. Fonte: Autores (2015).

Os dados também revelaram que a EA, na maioria das vezes, acontece por ações de projetos, disciplinas afins, iniciativa individual do professor ou interdisciplinarmente (FIGURA 2). A ação disciplinas afins revelou que 36,8\% dos trabalhos de EA nos currículos escolares são apresentados pelas disciplinas de Geografia, Ciências e Biologia. Valor similar foi encontrado para a ação de projetos $(34,2 \%)$, confirmando que este pode ser uma boa alternativa de se inserir a EA de forma interdisciplinar, se não for executado de maneira pontual.

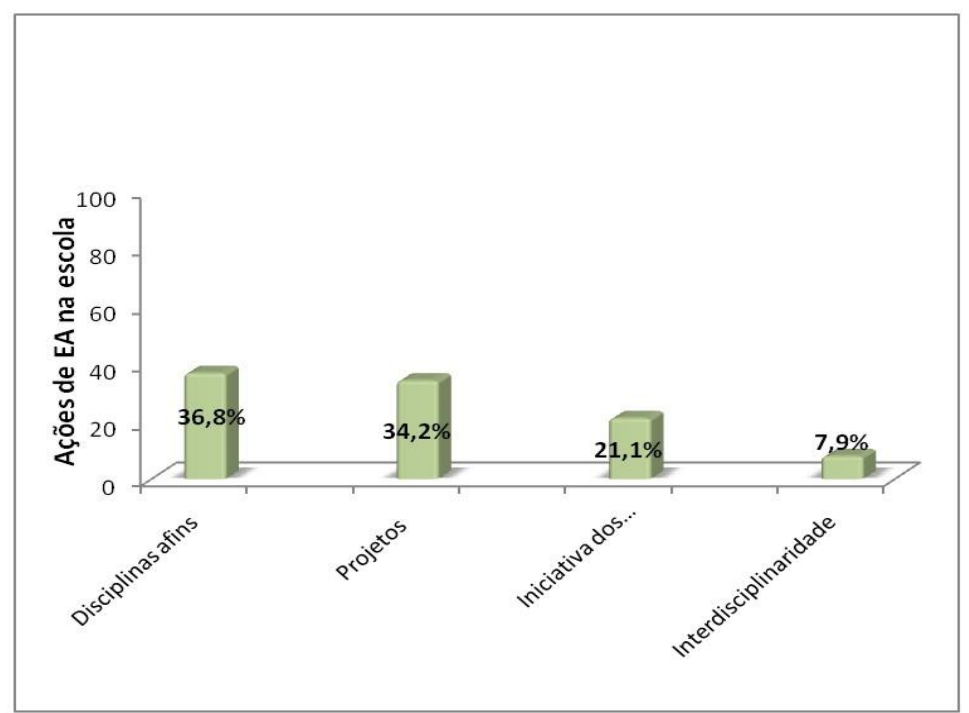

Figura 2 - Formas como a Educação Ambiental é trabalhada nas escolas pesquisadas. Fonte: Autores (2015)

A inserção da EA nos currículos por iniciativa dos professores atingiu um percentual de $21,1 \%$, o que é um dado preocupante, pois revela que as escolas não têm demonstrado preocupação com a temática ambiental e ainda delegam toda a responsabilidade do tema aos professores. Com relação à inserção da EA na escola, por meio da interdisciplinaridade, esta alcançou um percentual de apenas $7,9 \%$, o que demonstra a complexidade de se trabalhar envolvendo todas as disciplinas curriculares. 
As discussões acerca do espaço da EA no currículo escolar são muito importantes, visto que a escola é o ambiente propício para a formação do cidadão. Virgens (2011) afirma que escola deve interagir com as transformações ocorridas no ambiente que a rodeia para que a EA possa se instituir como prática educativa. A escola deve ainda proporcionar uma EA que propicie novas atitudes e comportamentos face ao consumo na nossa sociedade e de estimular a mudança de valores individuais e coletivos (JACOBI, 2007).

Em relação às ações de EA praticadas nas escolas, Jacobi (2007) afirma que as experiências interdisciplinares ainda são recentes e pouco relevantes, inclusive em nível de pós-graduação. O que prevalece na escola em relação à prática da EA são ações multidisciplinares, restringindo as questões socioambientais às disciplinas de geografia, biologia e ciências, ou seja, disciplinas que possuem afinidades com a temática ambiental.

Analisando os resultados das pesquisas mencionadas pode-se perceber que as escolas não estão alcançando os objetivos propostos pelos PCN's, isto porque 36,8\% dos trabalhos afirmaram serem as disciplinas afins a principal maneira como a EA é inserida nas escolas. Porém, é importante ressaltar que ao se delegar a responsabilidade da EA na escola às disciplinas com afinidade à temática ambiental, exclui-se a possibilidade de novos contextos que poderiam ser abordados por disciplinas que não possuem tanta afinidade assim.

As orientações dos PCN's é que a EA deve ser trabalhada de modo transversal, contínuo e permanente em todas as disciplinas (BRASIL, 1998). Porém, o que se pode observar é que os professores das disciplinas de Matemática, Língua Portuguesa, Física e Química, por exemplo, não se sentem à vontade em tratar de temas que são, muitas vezes, distantes das suas esferas de conhecimento. Situação, muitas vezes, agravada em razão da maioria das disciplinas escolares não possuírem recursos didáticos e metodológicos para que a EA se efetive nas escolas, assim como pela carência de conhecimentos específicos sobre o tema pelo corpo docente.

Almeida et al. (2012) realizaram a sua pesquisa com o objetivo de investigar a prática da EA em uma escola de Divisa Alegre - MG e, por meio de questionários aplicados aos professores da escola, chegaram à conclusão que, apesar de os docentes dessa instituição se declararem preocupados com o meio ambiente, a escola não realizava práticas de EA para os seus alunos. Segundo os professores, dessa instituição de ensino, a EA é promovida na escola principalmente por disciplinas afins como Biologia e Ciências. Estes mesmos autores afirmaram ainda que essa prática é reforçada pela inclusão do tema ambiental, apenas nos livros de Ciências.

A pesquisa intitulada "O que fazem as escolas que dizem que fazem Educação Ambiental", realizada pelo MEC durante o ano de 2005, também elencou as principais maneiras como a EA é trabalhada nas escolas brasileiras. Como pode ser observado na figura 3, os resultados seguem compatíveis com esta pesquisa. 


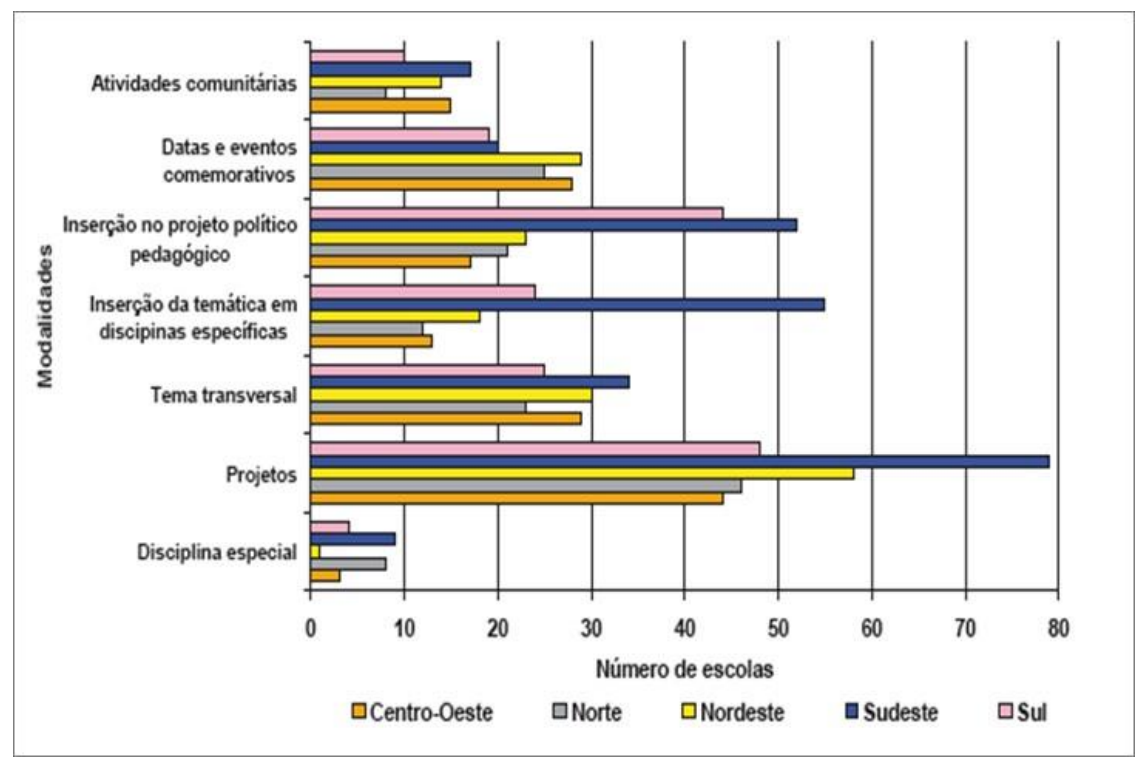

Figura 3 - Modalidades da Educação Ambiental nas escolas brasileiras.

Fonte: Trajber e Mendonça (2007).

A inserção da temática da EA por meio de disciplinas específicas alcançou altos resultados, principalmente na região sudeste do país. Trajber e Mendonça (2007) afirmam que na análise desses dados houve uma maior preponderância das disciplinas de Ciências Naturais e Geografia, o que evidencia a dependência que a EA apresenta pelas disciplinas chamadas afins.

A EA não pode se restringir somente a disciplinas como Geografia e Ciências, isso porque os problemas ambientais são muito complexos e possuem um caráter multidimensional, que possibilita que haja uma interação entre as diferentes fontes de conhecimento da escola (SILVA, 2008). É importante levar em consideração que os professores dessas disciplinas já sofrem com problemas significantes, como carga horária excessiva e exigências em relação aos conteúdos curriculares. E, delegar uma temática tão ampla aos professores dessas disciplinas é reduzir a sua importância e permitir que esta seja trabalhada apenas em datas comemorativas, como uma maneira de se sair da rotina.

Em $34,2 \%$ dos trabalhos mencionados nessa pesquisa bibliográfica, os projetos apareceram como principal maneira de se trabalhar a EA na escola. A inserção da EA no currículo escolar, por meio de projetos, é uma alternativa bastante comum nas escolas brasileiras. Trajber e Mendonça (2007) afirmam que a realização de projetos proporciona uma otimização e o aumento da presença da EA nas escolas. Conforme pode ser observado na figura 3, a modalidade projetos é uma das mais praticadas nas escolas brasileiras, principalmente nas regiões Sudeste e Nordeste do país.

Em relação aos projetos de EA, a pesquisa "O que fazem as escolas que dizem que fazem Educação Ambiental" também investigou quais são os temas mais trabalhados nos projetos das escolas brasileiras. Das 105 escolas que afirmaram desenvolver projetos de EA, 103 afirmaram que o principal tema abordado nos projetos é a água, 66 escolas afirmaram ser o lixo e a reciclagem, 30 escolas declararam ser a poluição e o saneamento básico.

Um dado surpreendente é que apenas uma escola afirmou tratar do tema Bioma em seus projetos. Isso é preocupante, porque uma maneira de fazer que o estudante se sinta inserido no meio ambiente é colocá-lo em contato com o seu meio, e isso é possível através do estudo do seu Bioma. Ademais, a EA deve proporcionar ao estudante que ele vivencie o meio ambiente e não que o veja como algo distante de sua realidade.

A realização de projetos de EA pode ser uma alternativa viável para a sua inserção nos currículos das escolas, porém os trabalhos científicos têm demonstrado que nem sempre esses projetos são interdisciplinares e com alcance a toda a comunidade escolar. Camelo (2011) em sua monografia, 
sobre a EA numa escola estadual de Pernambuco, constatou que apesar de bons projetos serem elaborados pela escola, esses ficam sem continuidade, visto que os referidos projetos, na maioria das vezes, ficam restritos a datas comemorativas.

Em seu trabalho intitulado Mapeamento dos Projetos de Educação Ambiental do Ensino Fundamental Caldeira et al. (2012) observaram que os projetos de EA das escolas pesquisadas são pontuais e não são continuados pelos membros da escola. Para estes autores, os projetos de EA podem ser excelentes recursos para o processo de ensino-aprendizagem no contexto escolar, mas eles precisam ser realizados de maneira que conecte todas as áreas da escola e abranjam um tempo considerável para que os seus resultados possam ser avaliados.

A utilização de projetos apresenta diversas vantagens para a comunidade escolar, visto que possibilita a quebra da rígida grade curricular, que muitas vezes parece impossível de ser ultrapassada. No entanto, apresenta também suas limitações, se não for executado de maneira a integrar todas as áreas curriculares da escola não consegue cumprir seu objetivo principal: a interdisciplinaridade.

Concepções similares foram defendidas por Vasconcelos (2013) ao afirmar que os projetos ainda merecem estudo e capacitação para que esta modalidade não se torne única alternativa metodológica possível no ambiente escolar e que não se tenha a ilusão de que se pode resolver todos os problemas de ensino e aprendizagem dos alunos.

Nos trabalhos analisados para essa pesquisa pode-se observar que $21,1 \%$ das escolas pesquisadas trabalham a EA apenas por iniciativa de alguns professores (SANTOS, 2007; ABREU et. al., 2008; MAFRA, 2010; SOUZA e SANTOS, 2012; TEIXEIRA e TALAMONI, 2012; REIS, 2013; VENDRUSCOLO et al., 2013; FRANÇA e GUIMARÃES, 2014). Esses docentes geralmente possuem alguma afinidade com as questões ambientais e procuram interligar os conteúdos de suas disciplinas com a EA.

Também declararam, em resposta aos questionários realizados pelos pesquisadores, que as suas escolas não realizam projetos de EA, nem fornecem quaisquer subsídios para a prática da EA na escola. Souza e Santos (2012) constataram que a escola não realiza práticas interdisciplinares, o que prejudica a inserção da EA no âmbito escolar e que os conteúdos referentes à EA são trabalhados em sala de aula, apenas em ocasiões específicas, como datas comemorativas.

Em sua dissertação de mestrado sobre a Formação em Educação Ambiental no município de Navegantes - SC, Mafra (2010), discorre que os professores das disciplinas de Ciências Naturais das escolas que fizeram parte de seu estudo, se sentem solitários em relação à prática de EA nas suas escolas. Como as iniciativas de EA geralmente partem deles, acabam ficando responsável por todo o andamento dos projetos.

Apenas 7,9\% das escolas pesquisadas declararam trabalhar a EA em função da interdisciplinaridade. Isso mostra o quanto é difícil implantar um EA interdisciplinar numa escola com um currículo totalmente disciplinar. Uma alternativa para o currículo disciplinar seria o currículo integrado, que busca uma articulação entre teoria e prática, o que acabaria com a fragmentação do conhecimento típica do currículo disciplinar. Porém, para que essa alternativa se torne pedagogicamente viável é necessário um trabalho em conjunto do corpo docente da escola ou da comunidade acadêmica (MEDEIROS e VALENTE, 2010).

Kusman e Rosa (2013) relataram que 30\% dos professores entrevistados trabalham a EA de forma interdisciplinar. Abreu e Rodrigues (2013) constataram que 4 das 7 escolas pesquisadas realizavam trabalhos de EA mediante a interdisciplinaridade e vinculados aos programas educacionais que desenvolvem. Resultado similar também foi observado por Barbosa (2009) ao explanar que a interdisciplinaridade também é praticada, apesar de que alguns professores relatarem a inserção da EA apenas na disciplina de Ciências. Por esta razão, a interdisciplinaridade se torna muito importante, pois segundo Beane (2003) ela se destaca como um sinônimo de integração curricular, se configurando então como um método pelo qual a integração curricular se efetiva.

A EA como tema transversal exige uma postura interdisciplinar no processo educativo. Porém Locatelli e Hendges (2005) alertam que a EA nas escolas tem sido confundida com ações pontuais em 
resposta ao que a sociedade espera da escola. Todavia, tais ações não conseguem gerar no cidadão, que está sendo formado, uma verdadeira consciência ambiental. Para que a EA se efetive, como prática educativa viável, é preciso que se proponha a elaboração de novos currículos que contemplem a EA de forma interdisciplinar.

Percebe-se que a EA nos currículos das escolas ainda carece de um lugar específico, onde possa se fundamentar como prática educativa. Dessa forma, o currículo escolar precisa se adequar para que a EA deixe de ser um conteúdo aplicado, apenas em datas comemorativas ou em projetos de curto prazo, mas que se efetive como prática permanente na escola e alcance o mesmo "status" das disciplinas ditas científicas.

Como pode ser observado na Figura 3, a pesquisa "O que fazem as escolas que dizem que fazem Educação Ambiental", também elencou outras modalidades de inserção da EA no currículo que não foram encontradas na pesquisa deste artigo. Assim, vale destacar a modalidade inserção no Projeto Político Pedagógico (PPP), sendo que a região Sudeste (mais de 50 das 80 escolas pesquisadas) tem nesta modalidade, a principal forma de inserção da EA na escola. E este é um fator positivo, visto que a escola que adota este tipo de modalidade possui a preocupação em efetivar a EA de forma permanente e contínua nas atividades escolares.

A modalidade disciplina especial foi a de menor incidência em todas as regiões do país devido, principalmente, às recomendações da Política Nacional de Educação Ambiental (PNEA), que não orienta a criação de disciplinas especiais de EA, mas orienta que esta seja trabalhada transversalmente em todos os níveis de ensino. E apesar do pequeno número de escolas, que dizem trabalhar a EA por meio de uma disciplina, muitos professores concebem essa prática como um espaço necessário para discutir a temática ambiental nas escolas.

Vários autores (BRASIL, 1998; GALLO, 2001; OLIVEIRA, 2007) defendem a EA interdisciplinar e transversal, ao passo que alguns, em menor número, a defendem como disciplina especial. A questão não é de simples resolução, pois os PCN's não fornecem subsídios teóricos, nem metodológicos para a inserção do tema transversal meio ambiente nas escolas e, isso deixa margem para que a escola procure outros meios para que a EA se efetive no currículo. Por outro lado, a disciplina especial possibilita que a EA tenha um espaço específico na unidade escolar, criando alternativas de diálogo em torno da questão ambiental (TRAJBER e MENDONÇA, 2007).

\section{Considerações Finais}

A pesquisa permitiu mostrar quais as ações de EA são desenvolvidas nas escolas brasileiras, evidenciando assim, a forma como acontece a inserção desta temática no currículo. A EA nas escolas deve obedecer as orientações dos PCN's e da PNEA, que diz que ela deve ser ofertada continuamente no ensino básico, de forma transversal e interdisciplinar. Porém, o que pode ser observado é que existem muitas dificuldades que limitam a inserção da EA na escola, dentre elas o currículo rigidamente disciplinar e a falta de suporte teórico e metodológico para o exercício da transversalidade.

Visualizou-se que, segundo os trabalhos analisados, a principal maneira de se trabalhar a EA nas escolas é por meio de disciplinas afins, como ciências e geografia. Como foi explanado anteriormente, isso revela que os ideais de transversalidade e interdisciplinaridade não estão sendo realizados, não por falta de vontades dos professores, mas porque é muito difícil desenvolver uma educação tão complexa como a EA em um contexto totalmente disciplinar.

A utilização de projetos é muito comum nas escolas brasileiras, sendo que é uma boa opção metodológica para quebrar a rigidez das disciplinas convencionais. Todavia, como foi observado, nem sempre essa opção tem sido trabalhada corretamente, porque muitas vezes os projetos ficam a cargo de dois ou três professores, geralmente de disciplinas com afinidade com as questões ambientais. Também se observou que muitas vezes a EA nas escolas é desenvolvida apenas por iniciativa de 
alguns professores, o que evidencia que as escolas, direção e equipe pedagógica, não tem se interessado efetivamente pela EA.

A interdisciplinaridade aparece como a maneira de inserção da EA nas escolas que é menos utilizada. Isso revela um quadro preocupante da escola básica brasileira, visto que a interdisciplinaridade é tida por teóricos e especialistas do assunto como a melhor forma de a EA dar frutos dentro do ambiente escolar.

Os resultados dessa pesquisa não diferem dos apresentados pela pesquisa nacional "O que fazem as escolas que dizem que fazem Educação Ambiental" desenvolvida pelo MEC, sobretudo ao considerar que os projetos seguidos da inserção por meio de disciplinas afins ainda são os principais mecanismos de desenvolvimento da EA no âmbito escolar.

\section{Referências}

ABREU, D. G., CAMPOS, M. L. A. M., AGUILAR, M. B. R. Educação Ambiental nas escolas da região de Ribeirão Preto (SP): concepções orientadoras da prática docente e reflexões sobre a formação inicial de professores de química. Revista Química Nova, v.31, n. 3, p. 688-693, 2008.

ABREU G. G., RODRIGUES, M. A. O tratamento de Educação Ambiental nas escolas públicas e privadas: um estudo de caso nas escolas do ensino fundamental da cidade de Uruçuí-PI. Enciclopédia Biosfera, v.9, n.16, p. 2371-2384, 2013.

ALMEIDA, O. S., MACEDO, D. F., SANTOS, V. C., ANJOS, K. F. Educação Ambiental e a prática educativa: estudo em uma escola estadual de Divisa Alegre-MG. Revista Metáfora Educacional, n.13, p. 156-173, 2012.

BARBOSA, A. P. S. Ambiente e Educação: concepções e práticas dos educadores nas escolas municipais de Colinas do Tocantins - TO [Dissertação]. Manaus: Universidade Federal do Amazonas, 2009. $110 \mathrm{p}$.

BEANE, J. A. Integração curricular: a essência de uma escola democrática. Currículo Sem Fronteiras, v.3, n.2, p. 91-110, 2003.

BRASIL. Ministério da Educação. Parâmetros Curriculares Nacionais (PCN): Temas Transversais. Brasília (BRASIL): MEC, 1998. 436 p.

BRASIL. Ministério da Educação. Programa Parâmetros em Ação Meio Ambiente na Escola. Brasília (BRASIL): MEC, 2001. 426 p.

BONOTTO, D. M. B. Formação docente em Educação Ambiental utilizando técnicas proletivas. Paidéia, v.15, n.32, p. 433 - 440, 2005.

CARVALHO, I. C. M. Educação ambiental: a formação do sujeito ecológico. 2.ed. São Paulo: Cortez Editora, 2006.

CARVALHO, I. C. M. A invenção do sujeito ecológico: identidade e subjetividade na formação dos educadores ambientais. In: SATO, M., CARVALHO, I. C. M. (orgs). Educação Ambiental: pesquisa e desafios. Porto Alegre: Artmed; 2005. p. 51-63.

CALDEIRA, C. S., NUNES, A. L. R, MORALES, A. G. Mapeamento de projetos de Educação Ambiental do ensino fundamental; 2012: IX Anped Sul, 2012. 
CAMELO, A. N. B. Educação Ambiental no ensino fundamental: um estudo de caso na escola de ensino fundamental John Kennedy em Guarabira/ PB [Monografia] Guarabira: Universidade Estadual da Paraíba; 2011.

CUBA, M. A. Educação ambiental nas escolas. ECCOM, v. 1, n.2, p.23-31, 2010.

FRANÇA, P. A. R., GUIMARÃES, M. G. V. A Educação Ambiental nas escolas municipais de Manaus (AM): um estudo de caso a partir da percepção dos discentes. Revista monografias ambientais, v.14, n.2, p. 3128-3138, 2014.

FERREIRA, C. F. B. Formação de professores: concepções e práticas pedagógicas de educação ambiental [Dissertação]. Rio de Janeiro: Instituto Federal de Educação, Ciência e Tecnologia do Rio de Janeiro, 2010. 105 p.

GALLO, S. Transversalidade e meio ambiente. 2001: Ciclo de palestras sobre o meio ambiente, 2001.

JACOBI, P. Educar na sociedade de risco: o desafio de construir alternativas. Pesquisa em Educação Ambiental, v. 2, n. 2, p. 49-65, 2007.

KUSMAN, R. A, ROSA, M. A. A Educação Ambiental no currículo: percepção dos professores das séries iniciais; 2013: XIV EPEA, 2013.

LEFF, E. Saber ambiental: sustentabilidade, racionalidade, complexidade, poder. 1 ed. Rio de Janeiro: Vozes; 2001.

LIMA, W. Aprendizagem e classificação social: um desafio aos conceitos. Fórum Crítico da Educação, v. 3, n.1, p. 29-55, 2004.

LÔBO, K. O. Ações pedagógicas e concepções sobre Educação Ambiental: um estudo de caso [Dissertação]. Fortaleza: Universidade Federal do Ceará; 2013. 113 p.

LOCATELLI, O. C., HENDGES, C. D. A. Educação Ambiental na perspectiva de um currículo interdisciplinar. Cadernos do CEOM, v. 21, n.29, p. 231-242, 2005.

MACEDO, E. F. Os Temas Transversais nos Parâmetros Curriculares Nacionais. Química Nova na Escola, n.8, p. 23-27, 1998.

MAFRA, A. I. A formação em Educação Ambiental no município de Navegantes - SC: entre o desejável e o possível [Dissertação]. Itajaí: Universidade do Vale do Itajaí; 2010. 120 p.

MEDEIROS, R. C. R., VALENTE, G. S. C. A prática docente reflexiva baseada no currículo integrado: uma questão de competências. Revista Ibero-americana de Educação, n. 54, p.1-9, 2010.

OLIVEIRA, H. M. A. Perspectiva dos educadores sobre o meio ambiente e a educação ambiental [Monografia). Niterói: Universidade Federal Fluminense; 2005.

OLIVEIRA, H. T. Ponto de partida: nebulosas à vista! In: MELLO, S. S, TRAJBER, R. (orgs.) Vamos cuidar do Brasil. Brasília: Ministério da Educação; 2007.

PÁDUA, S., TABANEZ, M. Educação ambiental: caminhos trilhados no Brasil. 1 ed. São Paulo: Ipê, 1998. 
REIGOTA, M. Meio ambiente e representação social. 6 ed. São Paulo: Cortez Editora, 2004.

REIS, A.D. Educação Ambiental e práticas no ensino fundamental na escola estadual Dr. Mário Chermont [Monografia]. Belém: Universidade Federal do Pará, 2013. 48 p.

ROSSI, S. Q, LEAL, M. C. Entre projetos, disciplinas e outras modalidades: algumas reflexões em Educação Ambiental; 2012: XII ENPEC, 2012.

SANTOS, C. P. A Educação Ambiental - um estudo de caso no município de Vitória da Conquista BA [Dissertação]. Ilhéus: Universidade Estadual de Santa Cruz; 2007. 115 p.

SILVA, A. S. A. A prática pedagógica da Educação Ambiental: um estudo de caso sobre o colégio Militar de Brasília [Dissertação]. Brasília: Universidade de Brasília; 2008.112 p.

SOUZA, R. M, SANTOS, M. M. Análise da prática pedagógica em Educação Ambiental no contexto de escola rural em Itaporanga DÁjuda - SE. Revista Vitas, n. 2, p. 1-17, 2012.

TRAJBER, R., MENDONÇA, P. R. O que fazem as escolas que dizem que fazem educação ambiental? Brasília: Secretaria de Educação Continuada, Alfabetização e Diversidade; 2007.

TEIXEIRA, L. A, TALAMONI, J. L. B. A relação teoria e prática e a Educação Ambiental na escola: pensando a formação docente na perspectiva da pedagogia histórico-crítica; 2012: XVI ENDIPE, 2012.

VASCONCELOS, P. A. S. Educação Ambiental e a química licenciatura: as concepções de professores. Revista monografias ambientais, v. 11, n.11 p. 2455-2464, 2013.

VENDRUSCULO, G. S., CONFORTI, A. C., MANICA, K., ARESI, D. Concepção e práticas de professores sobre a Educação Ambientais em escolas públicas. Revista Eletrônica do Mestrado em Educação Ambiental, v. 30, n.2, p. 49-63, 2013.

VIRGENS, R. A. A. Educação Ambiental no ambiente escolar [Monografia]. Brasília: Universidade de Brasília e Universidade Estadual de Goiás; 2011. 26 p. 